\title{
Research on Slope Stability Evaluation Based on Improved Set Pair Analysis Method: A Case of Tonglvshan Open-Pit Mine
}

\author{
Xiaojie Yang $\mathbb{D}^{1,2}$ Zhenli Hao $\mathbb{D}^{1,}{ }^{1,2}$ Gaotong Ma $\mathbb{D}^{1,2}$ and Gan Li $\mathbb{D}^{2,3}$ \\ ${ }^{1}$ State Key Laboratory for Geomechanics and Deep Underground Engineering, China University of Mining \& Technology, \\ Beijing 100083, China \\ ${ }^{2}$ School of Mechanics and Civil Engineering, China University of Mining \& Technology, Beijing 100083, China \\ ${ }^{3}$ Ningbo University, Ningbo 315000, China \\ Correspondence should be addressed to Zhenli Hao; zhenlihao@student.cumtb.edu.cn and Gan Li; ligan303@126.com
}

Received 5 September 2021; Accepted 30 September 2021; Published 18 October 2021

Academic Editor: Gan Feng

Copyright (C) 2021 Xiaojie Yang et al. This is an open access article distributed under the Creative Commons Attribution License, which permits unrestricted use, distribution, and reproduction in any medium, provided the original work is properly cited.

\begin{abstract}
In this paper, combined with fuzzy analytic hierarchy process (FAHP), information entropy theory, and set pair analysis (SPA) theory, an improved set pair analysis model (EFAHP-SPA) for open-pit mine slope stability evaluation based on entropy method and FAHP is proposed. Taking the east-side slope of Tonglvshan north open-pit mine in Daye as an example, the proposed method is verified. First, an open-pit mine slope stability evaluation index system with 14 indicators in 4 categories, namely the topography and geomorphology, geological structure, hydrogeology, and other factors, have been constructed. Second, the objective weight and subjective weight of each evaluation index are calculated by entropy and fuzzy analytic hierarchy process, and then the comprehensive weight of the evaluation index is estimated based on subjective weight and objective weight. Afterward, the singleindex connection degree between the evaluation index and the evaluation standard of the secondary subsystem is evaluated considering the improved set pair analysis theory, and the comprehensive connection degree of the system is obtained by combining it with the comprehensive weight of each evaluation index. Finally, the confidence criterion is established to discern the risk grade of slope stability in the east-side slope of the north open pit in Daye Tonglvshan mine. Moreover, case studies and comparisons of the proposed model with fuzzy comprehensive evaluation method and Entropy-SPA model were performed to confirm the validity and reliability. The results show that the evaluation results of the proposed EFAHP-SPA model are consistent with the actual situation of open-pit mines and the evaluation results of entropy-SPA model and are somewhat different from those of fuzzy comprehensive evaluation method. It indicates that the proposed EFAHP-SPA evaluation model can objectively evaluate the slope stability of the open-pit mine.
\end{abstract}

\section{Introduction}

With the increasing scale and depth of open-pit mining, the collapse and landslide geological disasters caused by mining occur frequently, which seriously affects the production safety of the mine as well as the surrounding buildings [1-3]. To reduce the loss of human life and property and ensure the normal operation of equipment, it is necessary to accurately evaluate the slope stability of open-pit mine. Slope stability evaluation is a multifactor, uncertain nonlinear problem, such as complicated external disturbance and the changeable geological environment, which makes the multifactor influence mechanism unable to be quantified, and there is no unified evaluation index and dimension for each influencing factor, and the acquisition of physical and mechanical parameters also has one-sidedness and uncertainty [4-6]. Therefore, the slope stability rating of open-pit mine has always been one of the main problems in slope engineering.

In the last few decades, with the continuous expansion of open-pit mining scale and the complexity of rock and soil storage environments, the traditional slope stability analysis theory faces a major challenge in engineering [7-9]. For instance, the engineering analogy method is a widely applicable qualitative analysis method for slope stability evaluation $[10,11]$. Owing to the uncertainty of influencing factors and the difference of engineering geological 
conditions, the evaluation process lacks a unified standard, leading to the results varying from person to person. The limit equilibrium method and numerical modelling are two of the most widely used quantitative analysis methods in slope stability evaluation $[10,12,13]$. Both give convenient solution of safety factor with clear physical meaning, but the application of the two methods in engineering practice has been limited by some defects. For limit equilibrium methods, certain hypothetical conditions need to be met in the calculation before they can be solved $[14,15]$. For numerical simulations, the accuracy of the evaluation results depends too much on the selection of geotechnical constitutive models and physical and mechanical parameters $[16,17]$. In reality, there are unstable slopes where the factor of safety of the slope is greater than 1 . It is precisely the existence of these uncertain factors that bring great challenges to the study of slope stability. With the deepening of research, there is a development trend of mutual reference and cross-integration of various nonlinear methods.

For this reason, many experts and scholars have put forward the multi-index evaluation models of slope stability combining qualitative and quantitative in recent years, such as fuzzy comprehensive evaluation $[18,19]$, analytic hierarchy process (AHP) [20], Topsis theory [21, 22], artificial neural networks (ANNs) $[23,24]$, and extension method $[25,26]$. Although the aforementioned research results have made great progress, there are still some limitations due to the different emphasis of various evaluation methods. For example, fuzzy comprehensive evaluation method cannot effectively solve the problem of information duplication caused by the correlation of evaluation indexes, which affects the evaluation accuracy; the weight determined by analytic hierarchy process (AHP) is greatly influenced by subjective factors. The deformation and instability of open-pit slopes occur under the common influence of many factors. Owing to the different mechanism of various influencing factors, it is inevitable to deal with multiple types of uncertainty in stability evaluation. However, facing the increasingly serious slope safety problems of open-pit mines, the conventional uncertainty analysis methods can only deal with the single type of uncertainty of fuzziness or randomness [10]. Therefore, some scholars tried to introduce the new theory into slope stability evaluation to obtain more accurate evaluation results. Set pair analysis (SPA) is a new method to deal with multiple uncertain information in recent years [27]. Lin [28] first introduced the set pair analysis theory into highway slope safety evaluation and combined it with analytic hierarchy process for established highway slope safety evaluation model. Qin and Qin [7] used the coupling model of fuzzy hierarchy and set pair analysis to evaluate the stability of high slope, but the index weight determined by the hierarchy method is highly subjective. Zhang et al. [4] introduced information entropy into the set pair analysis model and comprehensively evaluated the stability of openpit excavation slope using entropy weight set pair coupling model. Combined with the improved entropy weight set pair analysis and vehicle-mounted laser scanning technology, Liu et al. [29] put forward a highway slope risk evaluation model combining overall evaluation and local evaluation. Wang et al. [10] proposed a new multidimensional connection cloud model, which combined with set pair analysis (SPA) in connection number theory to improve the reliability and accuracy of slope stability evaluation. Taking 24 landslides in Fengjie County of Chongqing City as an example, Wang and Li [30] discussed the application of entropy-SPA model in landslide risk grade evaluation in mountainous areas. Yang et al. [31] compared and analyzed the application of set pair analysis method (SPA) and modified set pair analysis method (MSPA) in regional debris flow risk assessment through a case and considered that set pair analysis method was more suitable for debris flow risk assessment. The aforementioned research results provide a good reference for the comprehensive evaluation of multi-index slope stability. However, in analyzing the slope stability based on the set pair analysis model, either only the influence of subjective weight (such as analytic hierarchy process) on the evaluation results or only the influence of objective weight (such as entropy weight method) on the evaluation results is considered in the current research. Few studies use the set pair analysis model with subjective and objective comprehensive weight to comprehensively evaluate the slope stability.

However, in practical problems, the importance of index factors exists objectively and is affected by the subjective will of decision-makers. Only the subjective and objective comprehensive weight can fully reflect the importance of indicators. In view of this, the paper adopts the linear comprehensive weighting method to combine the subjective weight determined by the fuzzy analytic hierarchy process with the objective weight determined by the entropy weight method, so as to obtain the comprehensive weight of the open-pit slope stability evaluation. Taking the east-side slope of Tonglvshan north open-pit mine in Daye as the research object, aiming at the problems of uncertainty and unreasonable weight calculation in the stability evaluation of the open-pit slope, this paper puts forward an improved set pair analysis model based on information entropy and fuzzy analytic hierarchy process. Comprehensively consider the influencing factors of slope stability from the aspects of landform, engineering geological characteristics, meteorological and hydrological characteristics, and other factors, fully excavate the effective information of open-pit slope, and couple the comprehensive weight of each factor determined by fuzzy analytic hierarchy process and entropy weight method with the single-index connection degree to obtain the multi-index comprehensive connection degree of open-pit slope to be evaluated. Finally, the confidence criterion is used to evaluate the slope stability of open-pit mine. A comprehensive evaluation system for slope stability of open-pit mine is formed. It provides a new idea and reference for the stability evaluation of open-pit slope.

\section{Project Overview}

2.1. Engineering Geological Condition. Daye Tonglvshan mine is located about $3 \mathrm{~km}$ away from the southwest of Daye City, Hubei Province, about $30 \mathrm{~km}$ away from northeast of Huangshi City and $99 \mathrm{~km}$ away from northwest of Wuhan 
City. The administrative region is subordinate to Jinhu subdistrict office of Daye City. Its latitude and longitude range from $114^{\circ} 55^{\prime} 26^{\prime \prime} \mathrm{E} \sim 114^{\circ} 57^{\prime} 19^{\prime \prime} \mathrm{E}$ and $30^{\circ} 04^{\prime} 21^{\prime \prime} \mathrm{N} \sim 30^{\circ} 05^{\prime} 46^{\prime \prime} \mathrm{N}$, respectively. Mining area is characterized by low mountains, hills and lake basins. The topography of the mine is not undulating before mining, which shows the trend of high in south and low in north. With the exploitation of shallow resources, two adjacent opencast pits have been formed, which are about $1500 \mathrm{~m}$ in length from north to south and $500 \mathrm{~m}$ in width from east to west. The elevation of the slope top is between 30 and $55 \mathrm{~m}$, the lowest elevation of the pit bottom is $-175 \mathrm{~m}$, and the slope angle of the pit is about $46^{\circ} \sim 56.5^{\circ}$, of which the slope heights of the south open pit and the north open pit are $227 \mathrm{~m}$ and $142 \mathrm{~m}$, respectively. The Tonglvshan ancient copper mine site museum is located at the top of the slope on the east side of the north open-pit mine. As shown in Figure 1.

The east-side slope of north open-pit mine presents a protruding arc on the plane and a convex shape on the section. The slope gradient basically shows a trend of up gently and down steeply, and the closer the slope is to the slope foot, the steeper the slope is. Taking highway 3 as the boundary, the slope of the terrain above the highway is $20^{\circ} \sim 30^{\circ}$ and that below the highway is $50^{\circ} \sim 65^{\circ}$. The exposed strata in the region are relatively simple and mainly distributed in the lower Triassic Daye group, the lower Cretaceous Dasi formation, and the Quaternary loose strata. The basic structure of the mining area is NWW direction. Owing to the joint action of Neocathaysian system and the immersion of rock mass, the main structural line of the mining area is distributed in NNE direction. The marble trend of ore body and steep slope section is $\mathrm{N} 20^{\circ} \sim 25^{\circ} \mathrm{W}$, inclined to $\mathrm{SE}$, and the dip angle is $70^{\circ} \sim 80^{\circ}$. Most of the faults and joints near the slope are distributed in reverse slope direction and steep dip angle, either intersecting with the slope or inclined to the interior of the slope at steep dip angles. At present, there is no large-scale structure along the slope or close to the slope; most of the rock strata and ore bodies at the slope toe also occur along the reverse slope direction, which has little impact on the slope stability.

2.2. Hydrogeological Condition. The study area belongs to a typical subtropical continental monsoon climate, with abundant rainfall, and the annual average rainfall is $1387.24 \mathrm{~mm}$. The strata exposed in the mining area are mainly undifferentiated granodiorite porphyry, moderately weathered and strongly weathered granodiorite porphyry and the upper covered Quaternary loose bed. The strongly weathered rock and marble in the upper part of the slope belong to strong water-bearing body, the ore body and moderately weathered granodiorite porphyry containing joint dense zone belong to water-bearing body, while the nonweathered granodiorite porphyry has good integrity and belongs to relative water-resisting layer. Affected by mine drainage, a special relationship of recharge, runoff, and drainage has been formed. Atmospheric precipitation is the main source of shallow groundwater, and the marble aquifer which is easily recharged by atmospheric precipitation is the main recharge area of groundwater.

2.3. Status of Deformation and Failure of Slope. After prolonged mining activities, Tonglvshan mine has formed two open pits in the north and south. At present, the mining of the south open pit has been stopped and transferred to the north open-pit mine adjacent to the west of the ancient site for mining. Therefore, the problem of unstable slope in Tonglvshan mine is mainly concentrated near the ancient site of the east side of the north open pit. The potential unstable slope will seriously threaten the safety of Tonglvshan ancient copper mine site. However, due to the inadequate prevention and control measures for the slope of the open pit, the east slope of the north open pit has never been treated since its formation, which eventually resulted in two landslides near the No. 3 highway on the top of the east slope of the north open pit, with a landslide deformation area of about $5000 \mathrm{~m}^{2}$ [32].

For this purpose, comprehensive treatment was carried out on the north open-pit slope in 2010. After the implementation of the project, the stability of the east slope of the north open pit was improved and the further development trend of potentially unstable slope was slowed down. However, due to the risk factors affecting the slope still exist, such as the high and steep slope formed by open-pit mining, the goaf at the bottom of the ancient copper mine site, and blasting vibration during mining. Since 2012, due to the joint action of mining activities and rainfall, the deformation and cracking of the ancient copper mine site exhibition area and the outer wall of the museum have shown a trend of further expansion (Figure 2). In addition, the field investigation of the north open-pit mine shows that the lattice beam on the east slope of the open-pit mine has been partially damaged (Figure 2). Therefore, it is urgent to carry out comprehensive evaluation of multifactor influence mechanism of the north open-pit slope.

\section{Proposed Method}

3.1. Theory of Set Pair Analysis. The SPA method was originally introduced by Zhao [27], which is a quantitative analysis method for solving complex multidimensional certainty and uncertainty problems. The basic idea of SPA theory involves regarding the problem of uncertainties and certainties as an uncertain-certain system. This method analyzes the relationship between the uncertainty and the certainty of each factor or event from three aspects of identity-discrepancy-contrary employing the identity and contrary to describe the certainty of the system and discrepancy to describe the uncertainty of the system [33]. The core concepts of SPA are set pair and connection degree, in which, set pair refers to the pair composed of two sets with certain connection; the connection degree is used to quantitatively analyze the fuzzy uncertainty information in the system. Supposing that there are two sets $A$ and $B$ under condition $T$, and both have $N$ elements, then the connection degree of set pair $H(A, B)$ can be expressed as 


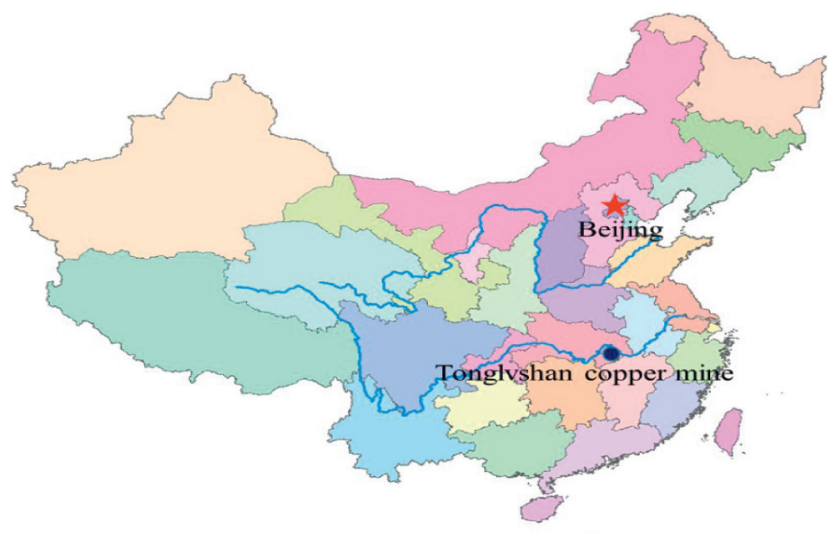

(a)

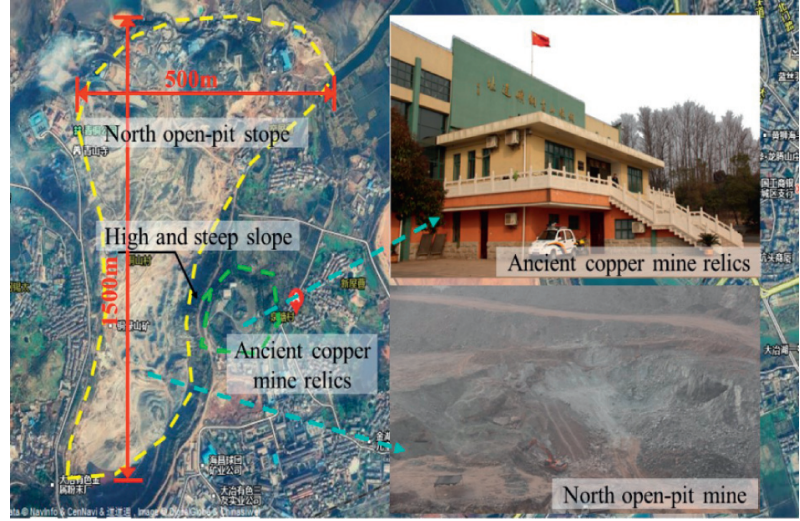

(b)

FIgURE 1: (a) Location map of Tonglvshan mine and (b) positional relationship between Tonglvshan mine and ancient copper mine site.

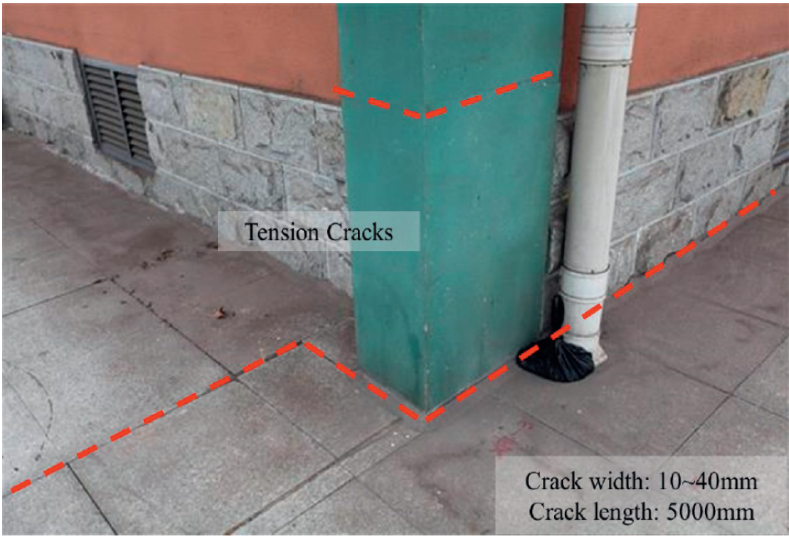

(a)

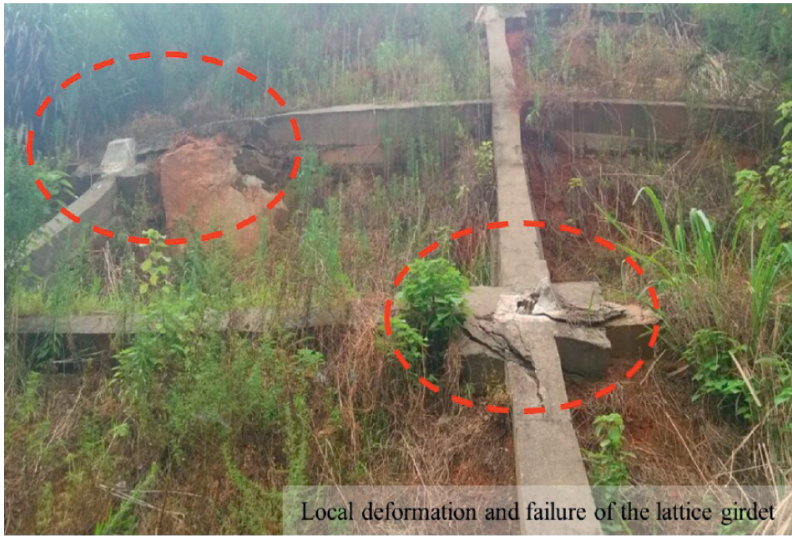

(b)

Figure 2: (a) Tension cracks in the exterior wall of museum and (b) local deformation and failure of lattice girder on the east-side slope of north open-pit mine [32].

$$
u=\frac{S}{N}+\frac{F}{N} i+\frac{P}{N} j=a+b i+c j
$$

where $u$ represents the connection degree of set pair $H(A, B) ; S, F$, and $P$ represent the number of identities, discrepancy, and contrary elements obtained by comparing the two set elements in the set pair; $a, b$, and $c$ represent the degree of identity, discrepancy, and contrary, respectively; $i$ is the uncertainty coefficient; and jis the contrary coefficient.

In traditional set pair analysis, the characteristics of two sets are usually classified into three categories: identity, discrepancy, and contrary. Although the ternary connection degree can meet the evaluation requirement of some simple things, in dealing with nonlinear complex objects with multidimensional information (such as open-pit slope), it cannot accurately and completely reflect the complex certainty and uncertainty relationship between the risk level of open-pit slope and various influencing factors, Then it affects the accuracy of risk assessment results of open-pit slope. To make a more accurate evaluation of practical engineering problems, the difference degree in the traditional set pair analysis theory is expanded and subdivided to obtain the system's multiple connection degrees based on the extensible principle of connection degree. It can be expressed as follows:

$$
\mu=\frac{S}{N}+\frac{F_{1}}{N} i_{1}+\frac{F_{2}}{N} i_{2}+\cdots+\frac{F_{n}}{N} i_{n}+\frac{P}{N} j .
$$

From the form of formulas (1), formula (2) can be simplified as

$$
\mu=a+b_{1} i_{1}+b_{2} i_{2}+\cdots+b_{n} i_{n}+c j,
$$

where $i_{1}, i_{2}, \ldots, i_{n}$ is the discrepancy coefficient; $F_{1}, F_{2}, \ldots, F_{n}$ is the difference characteristic number component in the set pair; $b_{1}, b_{2}, \ldots, b_{n}$ is the discrepancy degree component in the set pair, representing different in the discrepancy degree; and $j$ is the contrary coefficient.

\subsection{Improved Set Pair Analysis Model Based on Entropy and} FAHP. The core of slope stability evaluation of open-pit mine is to classify the slope stability of open-pit mine 
based on the similarity between the actual value of evaluation index and each grade standard. First, according to the specific characteristics of open-pit slope and previous research results, the open-pit slope stability evaluation index system and evaluation grade standard are established; second, FAHP and entropy weight method are used to calculate the subjective weight and objective weight of each evaluation index of the open-pit slope. Then the comprehensive weight of stability evaluation index is obtained by coupling the subjective weight and objective weight; third, based on the improved set pair analysis theory, the single-index connection degree between the evaluation index and the evaluation standard of the secondary subsystem is calculated. Combining with the comprehensive weight of each evaluation index to obtain the comprehensive connection degree of the system; finally, the stability grade of open-pit slope is divided by confidence criterion, and the validity of the EFAHPSPA model is verified by fuzzy comprehensive evaluation method and entropy-SPA model. The specific process is shown in Figure 3.

\subsubsection{Determining the Subjective Weight Using FAHP.} AHP is originally introduced by Saaty [34], which is a widely used method to determine the subjective weight of index. However, as the weight determined by AHP is greatly influenced by subjective factors, many scholars have introduced fuzzy set theory to improve it and put forward fuzzy analytic hierarchy process model $[35,36]$. Therefore, this paper adopts FAHP method to calculate the subjective weight of the evaluation index.

First, according to the characteristics of open-pit mine stability evaluation, the hierarchy structure model of openpit mine slope stability evaluation system is established by combining theoretical analysis, literature statistics, engineering analogy, and other methods. Based on expert experience and extensive literature analysis, the fuzzy complementary judgment matrix $A$ is constructed by pairwise comparing the importance of subsystems and their evaluation indexes. Fuzzy complementary judgment matrix $A=\left(a_{i j}\right)_{n \times n}$ satisfies the following properties: $a_{i i}=0.5$, $a_{i j}+a_{j i}=1,(i, j=1,2,3, \ldots, n)$, and $0 \leq a_{i j} \leq 1$, where $a_{i j}$ indicates the degree to which index $i$ is better than $j$. According to the weight calculation formula deduced by $\mathrm{Xu}$ [37], the weight of the open-pit slope stability evaluation subsystem and the fuzzy complementary judgment matrix of its evaluation indexes are calculated. The solution formula of subjective weight is

$$
\omega_{i}=\frac{\left(\sum_{j=1}^{n} a_{i j}+(n / 2)-1\right)}{[n(n-1)]} \quad(i=1,2,3, \ldots, n),
$$

where $\omega_{i}$ indicates the weight of $i$ th evaluation index of each subsystem of slope stability evaluation of open-pit mine.

Second, whether the weight of evaluation index obtained by formula (4) is reasonable or not, the consistency of fuzzy complementary judgment matrix should be tested. Chen and Zhao [38] proposed a method to test the consistency using the compatibility of fuzzy judgment matrix. The specific operations are as follows: if both matrices $A=\left(a_{i j}\right)_{n \times n}$ and $B=\left(b_{i j}\right)_{n \times n}$ are fuzzy judgment matrices, then the compatibility index of matrices $A$ and $B$ is

$$
I=(A, B)=\frac{1}{n^{2}} \sum_{i=1}^{n} \sum_{j=1}^{n}\left|a_{i j}+b_{j i}-1\right| .
$$

If $\omega=\left(\omega_{1}, \omega_{2}, \omega_{3}, \ldots, \omega_{n}\right)^{T}$ is the ranking vector of the fuzzy judgment matrix $A$, where $\sum_{j=1}^{n} \omega_{i}=1, \omega_{i} \geq 0,(i=$ $1,2,3, \ldots, n)$, then the characteristic matrix of the fuzzy judgment matrix $A$ is

$$
\omega^{*}=\left(\omega_{i j}\right)_{n \times n},
$$

where $\omega_{i j}=\omega_{i} /\left(\omega_{i}+\omega_{j}\right),(i, j=1,2,3, \ldots, n)$.

Then, the consistency test of fuzzy judgment matrix can be calculated by

$$
I=\left(A, \omega^{*}\right)=\frac{1}{n^{2}} \sum_{i=1}^{n} \sum_{j=1}^{n}\left|a_{i j}+\omega_{j i}^{*}-1\right| .
$$

Generally speaking, when $I<0.1$, the weight of the evaluation index of open-pit slope stability calculated is reasonable. Otherwise, it is necessary to readjust the value of the fuzzy complementary judgment matrix and repeat the aforementioned steps until the consistency check is satisfied.

\subsubsection{Determining the Objective Weight Using Entropy.} Entropy is a thermodynamic concept, originally introduced into information theory by Shannon, which is used to quantitatively describe the disorder, uncertainty, and instability of the system [39], which used to quantitatively describe the disorder, uncertainty, and instability of the system. Information entropy can effectively measure the size of effective information and reflect the relative importance of different evaluation indicators. The larger the entropy value of the evaluation factor, the smaller the entropy weight, indicating that the factor plays a smaller role in the comprehensive evaluation and is less important. Therefore, in this model, the entropy weight method is mainly used to determine the objective weight of each evaluation index [40]. The specific calculation process is as follows:

First, the evaluation matrix $C=\left(c_{i j}\right)_{m \times n}$ composed of $m$ slope evaluation samples and $n$ evaluation indexes is constructed, and the evaluation matrix $C$ is normalized to obtain the normalized evaluation matrix $R=\left(r_{i j}\right)_{m \times n}$. For the larger and safer index, there are

$$
r_{i j}=\frac{\left(c_{i j}-c_{\min }\right)}{\left(c_{\max }-c_{\min }\right)} .
$$

For the smaller and safer index, there are

$$
r_{i j}=\frac{\left(c_{\max }-c_{i j}\right)}{\left(c_{\max }-c_{\min }\right)} \text {. }
$$

The normalized evaluation matrix is 


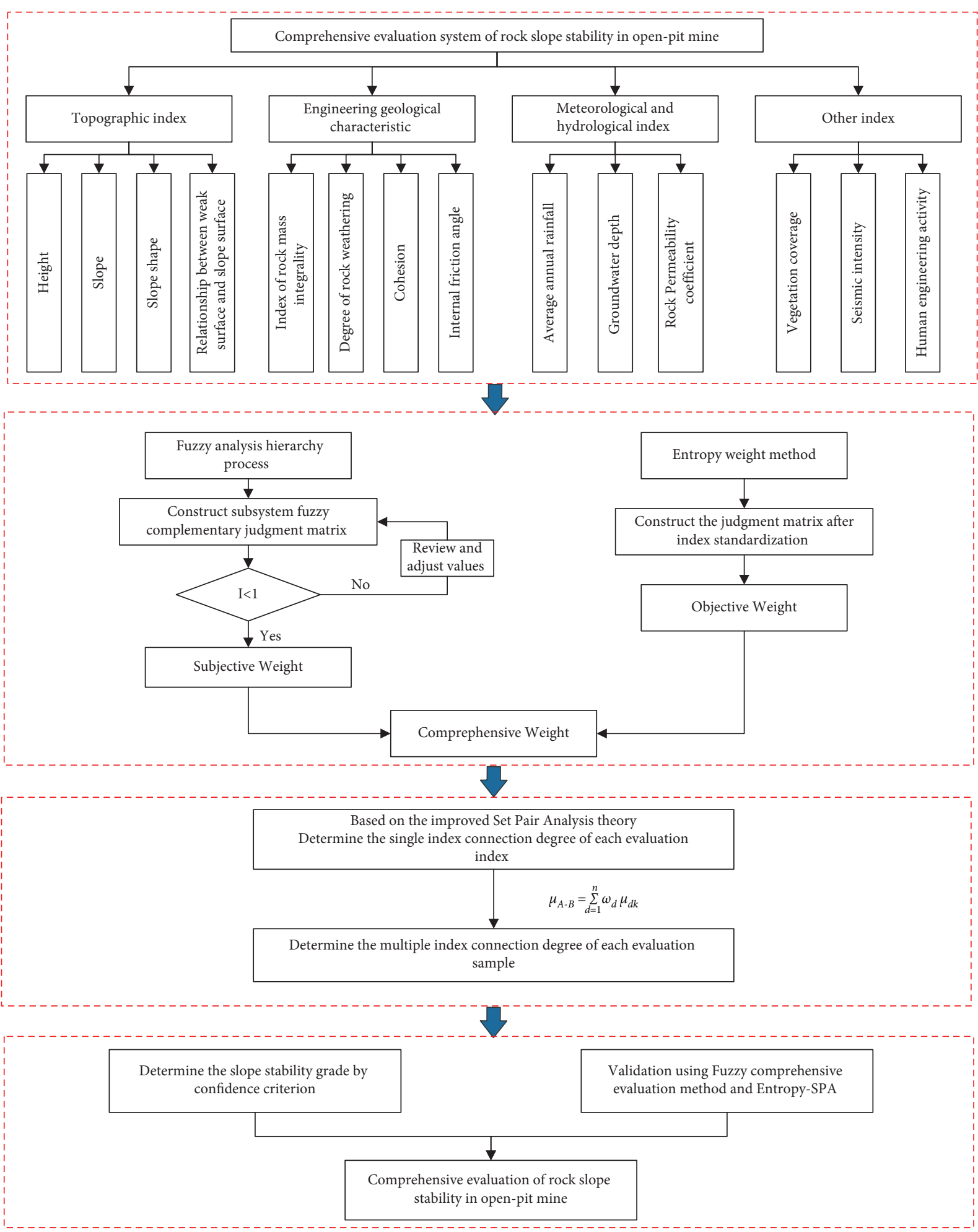

FIgURE 3: Flow chart of comprehensive evaluation of open-pit slope stability based on EFAHP-SPA model.

$$
R=\left(r_{i j}\right)_{m \times n}=\left[\begin{array}{cccc}
r_{11} & r_{12} & \cdots & r_{1 n} \\
r_{21} & r_{22} & \cdots & r_{2 n} \\
\vdots & \vdots & \ddots & \vdots \\
r_{m 1} & r_{m 2} & \cdots & r_{m n}
\end{array}\right] \quad(i=1,2, \ldots, m ; j=1,2, \ldots, n),
$$


where $c_{i j}$ is the measured value of the $j$ th evaluation index of theith evaluation sample, $c_{\max }$ and $c_{\min }$ are respectively the maximum and minimum values of different evaluation samples of the same evaluation index, and $r_{i j}$ is the normalized evaluation index value.

Second, taking the normalized evaluation matrix $R$ as the research object, according to the concept of traditional entropy, the entropy of the $j$ th evaluation index is defined as

$$
H_{j}=-\frac{1}{\ln m} \sum_{i=1}^{m} P_{i j} \ln P_{i j} \quad(i=1,2, \ldots, m ; j=1,2, \ldots, n),
$$

$$
P_{i j}=\frac{r_{i j}}{\sum_{i=1}^{m} r_{i j}},
$$

where when $P_{i j}=0, \ln P_{i j}$ has no practical significance, so formula (11) can be modified as

$$
P_{i j}=\frac{\left(1+r_{i j}\right)}{\sum_{i=1}^{m}\left(1+r_{i j}\right)} .
$$

Finally, the entropy weight of the $j$ th evaluation index is

$$
V_{j}=\frac{\left(1-H_{j}\right)}{\left(n-\sum_{j=1}^{n} H_{j}\right)},
$$

where $V_{j}$ is the entropy weight of the $j$ th evaluation index, and the entropy weight vector of the evaluation index is $V=\left(V_{1}, V_{2}, V_{3}, \ldots, V_{n}\right)^{T}$.

3.2.3. Determining the Comprehensive Weight. The subjective and objective weight vectors obtained by FAHP and entropy weight method are $\omega=\left(\omega_{1}, \omega_{2}, \omega_{3}, \ldots, \omega_{n}\right)^{T}$ and $V=\left(V_{1}, V_{2}, V_{3}, \ldots, V_{n}\right)^{T}$, respectively. Then, the subjective weight and objective weight are multiplied, synthesized, and normalized, and the comprehensive weight of each evaluation index of open-pit slope is

$$
W_{i}=\frac{\omega_{i} V_{i}}{\sum_{i=1}^{n} \omega_{i} V_{i}} \quad(i=1,2, \ldots, n),
$$

where $W_{i}$ is the comprehensive weight of the $i$ th evaluation index, and $i$ only represents the serial number of the evaluation index, without actual physical significance.

\subsubsection{Calculating Single-Index Connection Degree.}

Suppose that $s_{1}, s_{2}, \ldots, s_{k-1}, s_{k}$ is the threshold value corresponding to different evaluation grade standards for openpit slope, which are divided into $k$ grades and expressed in two forms. The specific grade classification standards are shown in Table 1 [4]. Owing to the fuzziness of the boundary of the threshold value, it is stipulated that if a single-index evaluation falls within a certain evaluation level range, it is regarded as the identity degree, then falling within the adjacent level is regarded as the discrepancy degree, and falling within the separated level range is regarded as the contrary degree, that is, the fuzziness of the level boundary
TABLE 1: Classification table of evaluation standard.

\begin{tabular}{lcc}
\hline Grading standard & \multicolumn{2}{c}{ Evaluation grade standard value } \\
& Form 1 & Form 2 \\
\hline 1 & $s_{1}$ & $<s_{1}$ \\
2 & $s_{2}$ & $s_{1} \sim s_{2}$ \\
$\ldots$ & $\ldots$ & $\ldots$ \\
$k-1$ & $s_{k-1}$ & $s_{k-2} \sim s_{k-1}$ \\
$k$ & $s_{k}$ & $>s_{k-1}$ \\
\hline
\end{tabular}

can be effectively solved through the discrepancy degree component [16].

Combined with the evaluation requirements of this study and the experience of previous studies, the risk grade of open-pit slope is divided into five grades, namely Grade I-very stable, Grade II-relatively stable, Grade III-basically stable, Grade IV-unstable, and Grade V-extremely unstable.

The measured value $x_{d}(d=1,2, \ldots, n)$ of the evaluation index of the open-pit mine slope to be evaluated is denoted as set $A_{d}$, and the corresponding evaluation standard is denoted as $B_{k}$, and then the set pair $H\left(A_{d}, B_{k}\right)$ is constructed. According to the improved set pair analysis theory, it can be known that the multivariate connection degree of set pair $H\left(A_{d}, B_{k}\right)$ is

$$
\mu=\frac{S}{N}+\frac{F_{1}}{N} i_{1}+\frac{F_{2}}{N} i_{2}+\frac{F_{3}}{N} i_{3}+\frac{P}{N} j=a+b_{1} i_{1}+b_{2} i_{2}+b_{3} i_{3}+c j .
$$

(1) The grade standard of first form, the multiple connection degree between the evaluation index, and the evaluation standard is

For the type where the larger the index is, the safer it is, the multiple connection degree is calculated by

$$
u_{d k}= \begin{cases}1+0 i_{1}+0 i_{2}+0 i_{3}+0 j & \left(x_{d} \geq s_{1}\right), \\ \frac{x_{d}-s_{2}}{s_{1}-s_{2}}+\frac{s_{1}-x_{d}}{s_{1}-s_{2}} i_{1}+0 i_{2}+0 i_{3}+0 j & \left(s_{2} \leq x_{d}<s_{1}\right), \\ 0+\frac{x_{d}-s_{3}}{s_{2}-s_{3}} i_{1}+\frac{s_{2}-x_{d}}{s_{2}-s_{3}} i_{2}+0 i_{3}+0 j & \left(s_{3} \leq x_{d}<s_{2}\right), \\ 0+0 i_{1}+\frac{x_{d}-s_{4}}{s_{3}-s_{4}} i_{2}+\frac{s_{3}-x_{d}}{s_{3}-s_{4}} i_{3}+0 j & \left(s_{4} \leq x_{d}<s_{3}\right), \\ 0+0 i_{1}+0 i_{2}+\frac{x_{d}-s_{5}}{s_{4}-s_{5}} i_{3}+\frac{s_{4}-x_{d}}{s_{4}-s_{5}} j & \left(s_{5} \leq x_{d}<s_{4}\right), \\ 0+0 i_{1}+0 i_{2}+0 i_{3}+1 j & \left(x_{d}<s_{5}\right) .\end{cases}
$$

For the type where the smaller the index is, the safer it is, the multiple connection degree is calculated by 


$$
u_{d k}= \begin{cases}1+0 i_{1}+0 i_{2}+0 i_{3}+0 j & \left(x_{d} \leq s_{1}\right), \\ \frac{s_{2}-x_{d}}{s_{2}-s_{1}}+\frac{x_{d}-s_{1}}{s_{2}-s_{1}} i_{1}+0 i_{2}+0 i_{3}+0 j & \left(s_{1}<x_{d} \leq s_{2}\right), \\ 0+\frac{s_{3}-x_{d}}{s_{3}-s_{2}} i_{1}+\frac{x_{d}-s_{2}}{s_{3}-s_{2}} i_{2}+0 i_{3}+0 j & \left(s_{2}<x_{d} \leq s_{3}\right), \\ 0+0 i_{1}+\frac{s_{4}-x_{d}}{s_{4}-s_{3}} i_{2}+\frac{x_{d}-s_{3}}{s_{4}-s_{3}} i_{3}+0 j & \left(s_{3}<x_{d} \leq s_{4}\right), \\ 0+0 i_{1}+0 i_{2}+\frac{s_{5}-x_{d}}{s_{5}-s_{4}} i_{3}+\frac{x_{d}-s_{4}}{s_{5}-s_{4}} j & \left(s_{4}<x_{d} \leq s_{5}\right), \\ 0+0 i_{1}+0 i_{2}+0 i_{3}+1 j & \left(x_{d}>s_{5}\right) .\end{cases}
$$

(2) The grade standard of second form, the multiple connection degree between the evaluation index, and the evaluation standard is:
For the type where the larger the index is, the safer it is, the multiple connection degree is calculated by

$$
u_{d k}= \begin{cases}1+0 i_{1}+0 i_{2}+0 i_{3}+0 j & \left(x_{d} \geq s_{1}\right), \\ \frac{2 x_{d}-s_{1}-s_{2}}{s_{1}-s_{2}}+\frac{2 s_{1}-2 x_{d}}{s_{1}-s_{2}} i_{1}+0 i_{2}+0 i_{3}+0 j & \left(\frac{s_{1}+s_{2}}{2} \leq x_{d}<s_{1}\right), \\ 0+\frac{2 x_{d}-s_{2}-s_{3}}{s_{1}-s_{3}} i_{1}+\frac{s_{1}+s_{2}-2 x_{d}}{s_{1}-s_{3}} i_{2}+0 i_{3}+0 j & \left(\frac{s_{2}+s_{3}}{2} \leq x_{d}<\frac{s_{1}+s_{2}}{2}\right), \\ 0+0 i_{1}+\frac{2 x_{d}-s_{3}-s_{4}}{s_{2}-s_{4}} i_{2}+\frac{s_{2}+s_{3}-2 x_{d}}{s_{2}-s_{4}} i_{3}+0 j & \left(\frac{s_{3}+s_{4}}{2} \leq x_{d}<\frac{s_{2}+s_{3}}{2}\right), \\ 0+0 i_{1}+0 i_{2}+\frac{2 x_{d}-2 s_{4}}{s_{3}-s_{4}} i_{3}+\frac{s_{3}+s_{4}-2 x_{d}}{s_{3}-s_{4}} j & \left(s_{4} \leq x_{d}<\frac{s_{3}+s_{4}}{2}\right), \\ 0+0 i_{1}+0 i_{2}+0 i_{3}+1 j & \left(x_{d}<s_{4}\right) .\end{cases}
$$

For the type where the smaller the index is, the safer it is, the multiple connection degree is calculated by formula (20) .

$$
u_{d k}= \begin{cases}1+0 i_{1}+0 i_{2}+0 i_{3}+0 j & \left(x_{d} \leq s_{1}\right), \\ \frac{s_{1}+s_{2}-2 x_{d}}{s_{2}-s_{1}}+\frac{2 x_{d}-2 s_{1}}{s_{2}-s_{1}} i_{1}+0 i_{2}+0 i_{3}+0 j & \left(s_{1}<x_{d} \leq \frac{s_{1}+s_{2}}{2}\right) \\ 0+\frac{s_{2}+s_{3}-2 x_{d}}{s_{3}-s_{1}} i_{1}+\frac{2 x_{d}-s_{1}-s_{2}}{s_{3}-s_{1}} i_{2}+0 i_{3}+0 j & \left(\frac{s_{1}+s_{2}}{2}<x_{d} \leq \frac{s_{2}+s_{3}}{2}\right) \\ 0+0 i_{1}+\frac{s_{3}+s_{4}-2 x_{d}}{s_{4}-s_{2}} i_{2}+\frac{2 x_{d}-s_{2}-s_{3}}{s_{4}-s_{2}} i_{3}+0 j & \left(\frac{s_{2}+s_{3}}{2}<x_{d} \leq \frac{s_{3}+s_{4}}{2}\right) \\ 0+0 i_{1}+0 i_{2}+\frac{2 s_{4}-2 x_{d}}{s_{4}-s_{3}} i_{3}+\frac{2 x_{d}-s_{3}-s_{4}}{s_{4}-s_{3}} j & \left(\frac{s_{3}+s_{4}}{2}<x_{d} \leq s_{4}\right) \\ 0+0 i_{1}+0 i_{2}+0 i_{3}+1 j & \left(x_{d}>s_{4}\right) .\end{cases}
$$


3.2.5. Calculating Multi-Index Comprehensive Connection Degree. There are two main methods to determine the comprehensive connection degree of multiple indicators, namely, average connection degree and weighted average connection degree [41]. The weighted average connection degree can consider the influence of the difference of evaluation indexes on the set connection degree, so the weighted average method is used to calculate the multi-index comprehensive connection degree in this paper. Coupling the comprehensive weight of the evaluation index calculated by formula (15) with the connection degree of each index, the comprehensive connection degree of multiple indexes is obtained as follows:

$$
\begin{aligned}
\mu_{A-B}= & \sum_{d=1}^{n} \omega_{d} \mu_{d k}=\sum_{d=1}^{n} \omega_{d} a_{d}+\sum_{d=1}^{n} \omega_{d} b_{d, 1} i_{1} \\
& +\sum_{d=1}^{n} \omega_{d} b_{d, 2} i_{2}+\sum_{d=1}^{n} \omega_{d} b_{d, 3} i_{3}+\sum_{d=1}^{n} \omega_{d} c_{d} j,
\end{aligned}
$$

where $\omega_{d}$ is the comprehensive weight of the $d$ th evaluation index.

$$
\text { Suppose that } f_{1}=\sum_{d=1}^{n} \quad \omega_{d} a_{d}, f_{2}=\sum_{d=1}^{n}
$$
$\omega_{d} b_{d, 1}, f_{3}=\sum_{d=1}^{n} \omega_{d} b_{d, 2}, f_{4}=\sum_{d=1}^{n} \omega_{d} b_{d, 3}, f_{5}=\sum_{d=1}^{n} \omega_{d} b_{d}$, then formula (22) $<\mathrm{u}\rangle</ \mathrm{u}>$ can be expressed as

$$
\mu_{A-B}=f_{1}+f_{2} i_{1}+f_{3} i_{2}+f_{4} i_{3}+f_{5} j,
$$

where $f_{1}$ is the possibility that the slope stability of open-pit mine belongs to Grade I, $f_{2}$ is the possibility that the slope stability of open-pit mine belongs to Grade II, $f_{3}$ is the possibility that the slope stability of open-pit mine belongs to Grade III, $f_{4}$ is the possibility that the slope stability of openpit mine belongs to Grade IV, and $f_{5}$ is the possibility that the slope stability of open-pit mine belongs to Grade V.

\subsection{Comprehensive Evaluation of Open-Pit Mine Slope.} To avoid the grade judgment distortion caused by taking the grade corresponding to the maximum multi-index comprehensive connection degree as the final judgment grade of open-pit slope in the process of slope stability rating using the maximum membership criterion and improve the evaluation accuracy of slope stability grade, to this end, the confidence criterion is introduced to evaluate the stability grade of open-pit slope in this paper.

$$
h_{k}=\left(f_{1}+f_{2}+f_{3}+\cdots+f_{k}\right)>\lambda,
$$

where $\lambda$ is the confidence, which is generally taken within $[0.5,0.7]$, the larger the value of $\lambda$, the conservative the slope stability evaluation results tend to be. For a given $\lambda$, when $h_{k}>\lambda$ and $h_{k-1} \leq \lambda$, the slope stability evaluation grade belongs to grade $k$.

\section{Engineering Application}

4.1. Establishment of Comprehensive Evaluation Index System for Open-Pit Slope. The stability of open-pit slope is comprehensively affected by the physical and mechanical properties of rock mass, geological structure, groundwater level and rainfall, mining, and other factors. Owing to the different action mechanism of various influencing factors, the failure of open-pit slope is complex and uncertain. Statistical data show that the instability and failure of openpit slope is not only related to the properties of rock and soil, but also affected by external interference factors to a great extent. Therefore, it is necessary to accurately select the slope evaluation index and evaluation standard in combination with the actual engineering situation.

Referring to the relevant specifications of open-pit slope design and a large number of literature [7, 18, 42], and combined with the geological survey data of the open-pit slope engineering, this paper constructs the open-pit slope stability evaluation index system, as show in Figure 3 . The comprehensive evaluation index system is mainly composed of a primary evaluation subsystem composed of topography and landforms, engineering geological characteristics, meteorological and hydrological characteristics and other factors, as well as several secondary subsystems subdivided by each subsystem, as shown in Table 2 . To meet the evaluation requirements of slope stability of open-pit mine, referring to the classification standard of rock slope proposed by Wang et al. [43], the slope stability is divided into five grades by single-factor method, namely very stableGrade I, relatively stable-Grade II, basically stable-Grade III, unstable-Grade IV, and extremely unstable-Grade V. Among them, the stability evaluation indexes and evaluation standards of open-pit mine slope in the study area are shown in Table 2.

Taking the east-side slope of the north open pit of Daye Tonglvshan mine as the research object, four representative typical profiles of the east-side slope of the north open pit are selected for comprehensive evaluation of slope stability. The profile location is shown in Figure 4. Combined with the engineering geological exploration data and the experience and opinions of experts, the value of the open-pit slope evaluation index is determined. Owing to the space limitation, this paper only lists the value of some evaluation indexes, as shown in Table 3. For the convenience of calculation, the quantitative values of each evaluation index in this study are the average value. For the quantitative index that can be quantified, the measured value of the evaluation index is directly used to calculate, while for the qualitative index that cannot be quantified directly, the quantitative value is determined by the expert qualitative evaluation method. Combined with the opinions of experts and scholars and previous research results, 0.1, 0.3, 0.5, 0.7, and 0.9 were selected as the quantitative value of the evaluation standard of the qualitative index [29].

4.2. Calculating the Comprehensive Weight. First, the subjective weight of each evaluation index is calculated by fuzzy analytic hierarchy process. Combined with expert opinions and the actual situation of open-pit slope, the importance of 14 evaluation indexes of four first-level subsystems and their corresponding second-level subsystems is compared in pairs, and the fuzzy complementary judgment matrix of each subsystem is constructed. In this paper, the quantitative scale 
TABle 2: Comprehensive evaluation index system and evaluation standard of slope stability in open-pit mine.

\begin{tabular}{|c|c|c|c|c|c|c|}
\hline \multirow{2}{*}{$\begin{array}{l}\text { First-class evaluation } \\
\text { index }\end{array}$} & \multirow{2}{*}{$\begin{array}{l}\text { Second-class evaluation } \\
\text { index }\end{array}$} & \multicolumn{5}{|c|}{ Evaluation standard } \\
\hline & & $\begin{array}{l}\text { Very stable } \\
\text { (I) }\end{array}$ & Relatively stable (II) & $\begin{array}{l}\text { Basically } \\
\text { stable (III) }\end{array}$ & Unstable (IV) & $\begin{array}{c}\text { Extremely } \\
\text { unstable (V) }\end{array}$ \\
\hline \multirow{4}{*}{$\begin{array}{l}\text { Topography and } \\
\text { landforms }\end{array}$} & Height $(\mathrm{m})$ & $0 \sim 30$ & $30 \sim 45$ & $45 \sim 60$ & $60 \sim 80$ & $>80$ \\
\hline & Slope $\left({ }^{\circ}\right)$ & $0 \sim 15$ & $15 \sim 25$ & $25 \sim 35$ & $35 \sim 45$ & $>45$ \\
\hline & Slope shape & $\begin{array}{l}\text { Concave } \\
\text { slope }\end{array}$ & $\begin{array}{l}\text { Concave and straight } \\
\text { mixed slope }\end{array}$ & $\begin{array}{l}\text { Straight } \\
\text { slope }\end{array}$ & $\begin{array}{l}\text { Convex and } \\
\text { straight mixed } \\
\text { slope }\end{array}$ & Convex slope \\
\hline & $\begin{array}{l}\text { Relationship between } \\
\text { weak surface and slope } \\
\text { surface }\end{array}$ & $\begin{array}{l}\text { Reverse } \\
\text { slope }\end{array}$ & Superimposed slope & Cross-slope & Skew slope & Dip slope \\
\hline \multirow{4}{*}{$\begin{array}{l}\text { Engineering geological } \\
\text { characteristic }\end{array}$} & $\begin{array}{l}\text { Index of rock mass } \\
\text { integrality }\end{array}$ & $>90$ & $75 \sim 90$ & $50 \sim 75$ & $30 \sim 50$ & $0 \sim 30$ \\
\hline & $\begin{array}{c}\text { Degree of rock weathering } \\
(\%)\end{array}$ & $0 \sim 5$ & $5 \sim 15$ & $15 \sim 25$ & $25 \sim 35$ & $>35$ \\
\hline & Cohesion $(\mathrm{kPa})$ & $>220$ & $120 \sim 220$ & $80 \sim 120$ & $50 \sim 80$ & $0 \sim 50$ \\
\hline & Internal friction angle $\left(^{\circ}\right)$ & $>37$ & $29 \sim 37$ & $21 \sim 29$ & $13 \sim 21$ & $0 \sim 13$ \\
\hline \multirow{3}{*}{$\begin{array}{l}\text { Meteorological and } \\
\text { hydrological index }\end{array}$} & $\begin{array}{l}\text { Average annual rainfall } \\
(\mathrm{mm})\end{array}$ & $0 \sim 300$ & $300 \sim 500$ & $500 \sim 800$ & $800 \sim 1200$ & $>1200$ \\
\hline & Groundwater depth (m) & Shallow & Shallower & Ordinary & Deeper & Deep \\
\hline & $\begin{array}{l}\text { Rock permeability } \\
\text { coefficient }(\mathrm{m} / \mathrm{d})\end{array}$ & $0 \sim 5$ & $5 \sim 15$ & $15 \sim 30$ & $30 \sim 45$ & $>45$ \\
\hline \multirow{3}{*}{ Other index } & Vegetation coverage & $>35$ & $25 \sim 35$ & $15 \sim 25$ & $5 \sim 15$ & $0 \sim 5$ \\
\hline & Seismic intensity & $0 \sim 2$ & $2 \sim 4$ & $4 \sim 6$ & $6 \sim 8$ & $>8$ \\
\hline & $\begin{array}{l}\text { Human engineering } \\
\text { activity }\end{array}$ & Weak & Weaker & Ordinary & Stronger & Strong \\
\hline
\end{tabular}

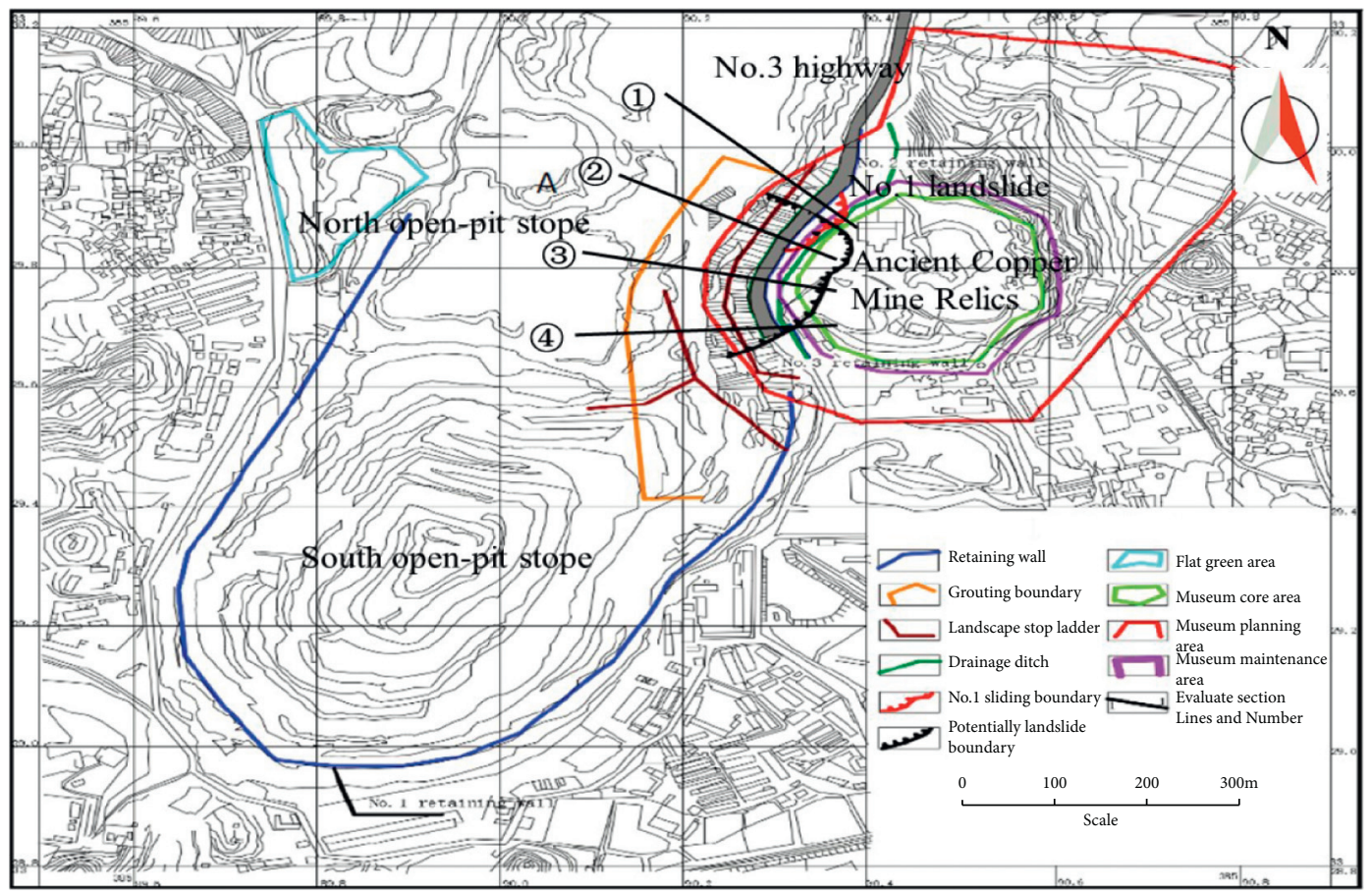

Figure 4: Profile distribution map for the slope stability evaluation in Tonglvshan open-pit mine.

TABLE 3: Partial evaluation index values of slope samples.

\begin{tabular}{lcccccccc}
\hline $\begin{array}{l}\text { Sample slope } \\
\text { number }\end{array}$ & $\begin{array}{c}\text { Height } \\
(\mathrm{m})\end{array}$ & $\begin{array}{c}\text { Slope } \\
\left({ }^{\circ}\right)\end{array}$ & $\begin{array}{c}\text { Slope } \\
\text { shape }\end{array}$ & $\begin{array}{c}\text { Degree of rock } \\
\text { weathering }\end{array}$ & $\begin{array}{c}\text { Index of rock mass } \\
\text { integrality }\end{array}$ & $\begin{array}{c}\text { Cohesion } \\
(\mathrm{kPa})\end{array}$ & $\begin{array}{c}\text { Internal friction } \\
\text { angle }\left(^{\circ}\right)\end{array}$ & $\begin{array}{c}\text { Average annual } \\
\text { rainfall }(\mathrm{mm})\end{array}$ \\
\hline 1 & 74.5 & 56 & 0.6 & 17.2 & 57 & 181.5 & 27 & 1328.7 \\
2 & 105.2 & 53 & 0.65 & 20.4 & 43 & 149.2 & 25.6 & 1328.7 \\
3 & 108 & 51 & 0.75 & 22.4 & 36 & 149.2 & 25.6 & 1328.7 \\
4 & 110.6 & 54 & 0.75 & 23.6 & 32 & 149.2 & 25.6 & 1328.7 \\
\hline
\end{tabular}


is given by the $0.1 \sim 0.9$ scale method proposed by $\mathrm{Xu}$ [37]. Then the fuzzy complementary judgment matrix of subsystems at all levels is

$$
\begin{aligned}
& A_{s}=\left[\begin{array}{llll}
0.5 & 0.4 & 0.6 & 0.7 \\
0.6 & 0.5 & 0.7 & 0.8 \\
0.4 & 0.3 & 0.5 & 0.6 \\
0.3 & 0.2 & 0.4 & 0.5
\end{array}\right], \\
& A_{s}^{1}=\left[\begin{array}{cccc}
0.5 & 0.6 & 0.4 & 0.7 \\
0.4 & 0.5 & 0.6 & 0.7 \\
0.6 & 0.4 & 0.5 & 0.8 \\
0.3 & 0.3 & 0.2 & 0.5
\end{array}\right], \\
& A_{s}^{2}=\left[\begin{array}{llll}
0.5 & 0.6 & 0.3 & 0.3 \\
0.4 & 0.5 & 0.3 & 0.3 \\
0.7 & 0.7 & 0.5 & 0.5 \\
0.7 & 0.7 & 0.5 & 0.5
\end{array}\right], \\
& A_{s}^{3}=\left[\begin{array}{lll}
0.5 & 0.6 & 0.4 \\
0.4 & 0.5 & 0.3 \\
0.6 & 0.7 & 0.5
\end{array}\right] \text {, } \\
& A_{s}^{4}=\left[\begin{array}{lll}
0.5 & 0.4 & 0.3 \\
0.6 & 0.5 & 0.4 \\
0.7 & 0.6 & 0.5
\end{array}\right] \text {. }
\end{aligned}
$$

$$
R=\left[\begin{array}{llllllllllllll}
1.00 & 0.00 & 1.00 & 0.00 & 1.00 & 1.00 & 1.00 & 1.00 & 0.00 & 1.00 & 0.00 & 0.00 & 0.00 & 1.00 \\
0.15 & 0.60 & 0.67 & 0.00 & 0.44 & 0.50 & 0.00 & 0.00 & 0.00 & 0.50 & 0.50 & 0.00 & 0.00 & 0.40 \\
0.07 & 1.00 & 0.00 & 0.00 & 0.16 & 0.19 & 0.00 & 0.00 & 0.00 & 0.25 & 1.00 & 0.00 & 0.00 & 0.00 \\
0.00 & 0.40 & 0.00 & 0.00 & 0.00 & 0.00 & 0.00 & 0.00 & 0.00 & 0.00 & 1.00 & 0.00 & 0.00 & 0.00
\end{array}\right]
$$

Finally, the subjective weight (Table 4) and objective weight (Table 5) calculated by fuzzy analytic hierarchy process and entropy weight method are combined by formula (15) to obtain the comprehensive weight of each evaluation index. The comprehensive weight of slope stability evaluation index of open-pit mine is shown in Table 5 .

\subsection{Determination of Multi-Index Comprehensive Connection} Degree of Open-Pit Slope. To determine the multi-index comprehensive connection degree of open-pit slope, it is necessary to calculate the single-index connection degree first. The measured value $x_{d}(d=1,2, \ldots, n)$ of the slope evaluation index of the open-pit mine to be evaluated is recorded as set $A_{d}$, that is, slope height set $A_{1}$, slope set $A_{2}$, slope shape set $A_{3}$, relationship between weak surface and slope set $A_{4}$, rock mass integrity set $A_{5}$, rock mass weathering degree set $A_{6}$, cohesion set $A_{7}$, internal friction angle set $A_{8}$, annual average rainfall set $A_{9}$, groundwater buried depth set $A_{10}$, rock permeability coefficient set $A_{11}$,
$A_{s}, A_{s}^{1}, A_{s}^{2}, A_{s}^{3}$, and $A_{s}^{4}$ were substituted into formulas (4) and (7) respectively for weight calculation and consistency test of evaluation indexes of each subsystem. By combining the hierarchical single ranking weight of the primary subsystem and the hierarchical single ranking weight of its corresponding secondary subsystem, the total ranking weight of each evaluation index is the subjective weight of each evaluation index. See Table 4 for the subjective weight of each evaluation index and the consistency test index of its corresponding judgment matrix. The subjective weight of each evaluation index and the consistency test index of its corresponding judgment matrix are shown in Table 5. It can be seen from the table that the compatibility index of each subsystem is less than 0.1. Therefore, it is considered that the subjective weight of the calculated open-pit mine stability evaluation index is acceptable.

Second, the measured values of the evaluation indexes of four slope samples are normalized by formulas (8) to (10), and the normalized judgment matrix $R$ is obtained. Then, the judgment matrix is substituted into formulas (11) to (14) to calculate the objective weight of each evaluation index. The objective weight and entropy of the evaluation index are shown in Table 5 . When the entropy value of a certain index is 1 , it indicates that the evaluation index values of the four slope samples are the same. For example, the multiyear average rainfall in the evaluation index is $1328.7 \mathrm{~mm}$. vegetation coverage set $A_{12}$, seismic activity set $A_{13}$, and human engineering activity set $A_{14}$, record the corresponding evaluation criteria as $B_{k}(k=1,2,3,4,5)$. Taking the Grade-I evaluation standard as the reference standard and based on the improved set pair analysis theory, the evaluation index values of the slope to be evaluated are substituted into formulas (16) and (20), and the five-element connection degree of the set pair $H\left(A_{d}, B_{k}\right)$, $(d=1,2,3, \ldots, 14)$ of 14 evaluation indexes is calculated. The single-index connection degree of four open-pit slope samples is shown in Tables 6 and 7.

After the single-index connection degree of each evaluation index is obtained, the comprehensive weight calculated earlier and the single-index connection degree of each evaluation index are substituted into formulas (21) to (23), and the comprehensive connection degree of the evaluation index can be obtained through calculation. Taking slope sample no. 1 as an example, the comprehensive weight of the evaluation index and the single-index connection degree of sample no. 1 are substituted into formula (21): 
TABLE 4: Subjective weight of evaluation index and consistency test index of judgment matrix.

\begin{tabular}{|c|c|c|c|c|c|c|}
\hline \multirow{2}{*}{ First-class evaluation index } & \multicolumn{2}{|c|}{$\begin{array}{l}\text { Fuzzy analytical } \\
\text { hierarchy process }\end{array}$} & \multirow{2}{*}{ Second-class evaluation index } & \multicolumn{2}{|c|}{$\begin{array}{l}\text { Fuzzy analytical } \\
\text { hierarchy process }\end{array}$} & \multirow{2}{*}{$\begin{array}{l}\text { Subjective } \\
\text { weight }\end{array}$} \\
\hline & $\begin{array}{l}\text { Weight of } \\
\text { subsystem }\end{array}$ & $I$ & & $\begin{array}{l}\text { Weight of } \\
\text { subsystem }\end{array}$ & $I$ & \\
\hline \multirow{4}{*}{ Topographic index } & \multirow{4}{*}{0.267} & \multirow{8}{*}{0.083} & Height $(\mathrm{m})$ & 0.267 & \multirow{4}{*}{0.093} & 0.071 \\
\hline & & & Slope $\left({ }^{\circ}\right)$ & 0.267 & & 0.071 \\
\hline & & & Slope shape & 0.275 & & 0.073 \\
\hline & & & $\begin{array}{l}\text { Relationship between weak surface and } \\
\text { slope surface }\end{array}$ & 0.192 & & 0.051 \\
\hline \multirow{4}{*}{$\begin{array}{l}\text { Engineering geological } \\
\text { characteristic }\end{array}$} & \multirow{4}{*}{0.300} & & Index of rock mass integrality & 0.225 & \multirow{4}{*}{0.077} & 0.068 \\
\hline & & & Degree of rock weathering (\%) & 0.208 & & 0.063 \\
\hline & & & Cohesion $(\mathrm{kPa})$ & 0.283 & & 0.085 \\
\hline & & & Internal friction angle $\left({ }^{\circ}\right)$ & 0.283 & & 0.085 \\
\hline \multirow{3}{*}{$\begin{array}{l}\text { Meteorological and } \\
\text { hydrological index }\end{array}$} & \multirow{3}{*}{0.233} & & Average annual rainfall (mm) & 0.333 & \multirow{3}{*}{0.055} & 0.078 \\
\hline & & & Groundwater depth $(\mathrm{m})$ & 0.283 & & 0.066 \\
\hline & & & Rock permeability coefficient $(\mathrm{m} / \mathrm{d})$ & 0.383 & & 0.089 \\
\hline \multirow{3}{*}{ Other index } & \multirow{3}{*}{\multicolumn{2}{|c|}{0.200}} & Vegetation coverage & 0.283 & \multirow{3}{*}{0.055} & 0.057 \\
\hline & & & Seismic intensity & 0.333 & & 0.067 \\
\hline & & & Human engineering activity & 0.383 & & 0.077 \\
\hline
\end{tabular}

TABLE 5: Objective weight and comprehensive weight of evaluation index.

\begin{tabular}{lcccc}
\hline First-class evaluation index & Second-class evaluation index & Entropy & Objective weight & Comprehensive weight \\
\hline & Height $(\mathrm{m})$ & 0.968 & 0.107 & 0.101 \\
Topographic index & Slope $\left(^{\circ}\right)$ & 0.979 & 0.072 & 0.068 \\
& Slope shape & 0.966 & 0.114 & 0 \\
& Relationship between weak surface and slope & 1 & 0.110 & 0 \\
\hline \multirow{2}{*}{ Engineering geological characteristic } & Index of rock mass integrality & 0.974 & 0.087 & 0.077 \\
& Degree of rock weathering (\%) & 0.975 & 0.084 & 0.070 \\
& Cohesion (kPa) & 0.961 & 0.132 & 0.148 \\
Meteorological and hydrological & Internal friction angle $\left(^{\circ}\right)$ & 0.961 & 0.132 & 0.148 \\
index & Average annual rainfall (mm) & 1 & 0 & 0 \\
& Groundwater depth (m) & 0.977 & 0.079 & 0.069 \\
Other index & Rock permeability coefficient (m/d) & 0.975 & 0.085 & 0.100 \\
& Vegetation coverage & 1 & 0 & 0 \\
\hline
\end{tabular}

TABLE 6: Single-index connection degree of evaluation sample nos. 1 and 2.

\begin{tabular}{|c|c|c|c|c|c|c|c|c|c|c|}
\hline \multirow{2}{*}{ Evaluation index set } & \multicolumn{5}{|c|}{ Evaluation sample no. 1} & \multicolumn{5}{|c|}{ Evaluation sample no. 2} \\
\hline & $a$ & $b_{1}$ & $b_{2}$ & $b_{3}$ & $c$ & $a$ & $b_{1}$ & $b_{2}$ & $b_{3}$ & $c$ \\
\hline$\overline{A_{1}}$ & 0 & 0 & 0 & 0.550 & 0.450 & 0 & 0 & 0 & 0 & 1 \\
\hline$A_{2}$ & 0 & 0 & 0 & 0 & 1 & 0 & 0 & 0 & 0 & 1 \\
\hline$A_{3}$ & 0 & 0 & 0.500 & 0.500 & 0 & 0 & 0 & 0.250 & 0.750 & 0 \\
\hline$A_{4}$ & 1 & 0 & 0 & 0 & 0 & 1 & 0 & 0 & 0 & 0 \\
\hline$A_{5}$ & 0 & 0 & 0.756 & 0.244 & 0 & 0 & 0 & 0.133 & 0.867 & 0 \\
\hline$A_{6}$ & 0 & 0.280 & 0.720 & 0 & 0 & 0 & 0 & 0.960 & 0.040 & 0 \\
\hline$A_{7}$ & 0.230 & 0.770 & 0 & 0 & 0 & 0 & 0.703 & 0.297 & 0 & 0 \\
\hline$A_{8}$ & 0 & 0.250 & 0.750 & 0 & 0 & 0 & 0.075 & 0.925 & 0 & 0 \\
\hline$A_{9}$ & 0 & 0 & 0 & 0 & 1 & 0 & 0 & 0 & 0 & 1 \\
\hline$A_{10}$ & 0 & 0.750 & 0.250 & 0 & 0 & 0 & 0 & 0.750 & 0.250 & 0 \\
\hline$A_{11}$ & 1 & 0 & 0 & 0 & 0 & 1 & 0 & 0 & 0 & 0 \\
\hline$A_{12}$ & 0 & 0.300 & 0.700 & 0 & 0 & 0 & 0.300 & 0.700 & 0 & 0 \\
\hline$A_{13}$ & 0 & 0 & 0.500 & 0.500 & 0 & 0 & 0 & 0.500 & 0.500 & 0 \\
\hline$A_{14}$ & 0.400 & 0.600 & 0 & 0 & 0 & 0 & 0 & 0.900 & 0.100 & 0 \\
\hline
\end{tabular}


TABLE 7: Single-index connection degree of evaluation sample nos. 3 and 4.

\begin{tabular}{lcccccccccc}
\hline \multirow{2}{*}{ Evaluation index set } & \multicolumn{4}{c}{ Evaluation sample no. 3} & \multicolumn{5}{c}{ Evaluation sample no. 4} \\
& $a$ & $b_{1}$ & $b_{2}$ & $b_{3}$ & $c$ & $a$ & $b_{1}$ & $b_{2}$ & $b_{3}$ & $c$ \\
\hline$A_{1}$ & 0 & 0 & 0 & 0 & 1 & 0 & 0 & 0 & 0 & 1 \\
$A_{2}$ & 0 & 0 & 0 & 0 & 1 & 0 & 0 & 0 & 0 & 1 \\
$A_{3}$ & 0 & 0 & 0 & 0.750 & 0.250 & 0 & 0 & 0 & 0.750 & 0.250 \\
$A_{4}$ & 1 & 0 & 0 & 0 & 0 & 1 & 0 & 0 & 0 & 0 \\
$A_{5}$ & 0 & 0 & 0 & 0.600 & 0.400 & 0 & 0 & 0 & 0.200 & 0.800 \\
$A_{6}$ & 0 & 0 & 0.760 & 0.240 & 0 & 0 & 0 & 0.640 & 0.360 & 0 \\
$A_{7}$ & 0 & 0.703 & 0.297 & 0 & 0 & 0 & 0.703 & 0.297 & 0 & 0 \\
$A_{8}$ & 0 & 0.075 & 0.925 & 0 & 0 & 0 & 0.075 & 0.925 & 0 & 0 \\
$A_{9}$ & 0 & 0 & 0 & 0 & 1 & 0 & 0 & 0 & 0 & 1 \\
$A_{10}$ & 0 & 0 & 0.250 & 0.750 & 0 & 0 & 0 & 0 & 0.750 & 0.250 \\
$A_{11}$ & 1 & 0 & 0 & 0 & 0 & 1 & 0 & 0 & 0 & 0 \\
$A_{12}$ & 0 & 0.300 & 0.700 & 0 & 0 & 0 & 0.300 & 0.700 & 0 & 0 \\
$A_{13}$ & 0 & 0 & 0.500 & 0.500 & 0 & 0 & 0 & 0.500 & 0.500 & 0 \\
$A_{14}$ & 0 & 0 & 0 & 0.900 & 0.100 & 0 & 0 & 0 & 0.900 & 0.100 \\
\hline
\end{tabular}

$$
\mu_{1}=0.177+0.288 i_{1}+0.293 i_{2}+0.129 i_{3}+0.113 j
$$

From formula (22), $f_{1}=0.177, f_{2}=0.288, f_{3}=0.293$, $f_{4}=0.129$, and $f_{5}=0.113$. Then, based on the confidence criterion, the stability of open-pit slope can be comprehensively evaluated. The comprehensive connection degree of other open-pit slope evaluation indexes is shown in Table 8.

\section{Results Analysis and Discussion}

5.1. Results Analysis. The confidence degree judgment results of slope stability of each open-pit mine are calculated by formula (23), as shown in Table 9. Taking slope sample no. 1 as an example, the determination process of slope stability grade is explained in detail. The confidence $\lambda \in[0.5,0.7]$. No matter what value $a$ takes in the interval, it can be seen from Table 9 that the slope of sample no. 1 has $f_{1}+f_{2}<\lambda, f_{1}+f_{2}+f_{3}>\lambda$. Therefore, whether the confidence is determined or not, we can determine that the stability grade of slope sample no. 1 is basically stable (Grade III). Among them, the greater the value of $\lambda$, the more conservative the result of slope stability evaluation.

Combined with the previous research results [30], select the confidence $\lambda=0.6$, and the stability judgment results of the other three sample slopes are shown in Table 9. It can be seen from Table 9 that the stability grades of slope samples no. 1 to no. 4 are basically stable (Grade III), basically stable (Grade III), unstable (Grade IV), and unstable (Grade IV). The stability of slope samples no. 3 to 4 is poor. The $f_{1}+$ $f_{2}+f_{3}+f_{4}$ values of slope samples no. 3 and 4 are 0.762 and 0.714, respectively, both of which have $f_{1}+f_{2}+f_{3}+f_{4}>\lambda=0.7$, indicating that although the stability grades of slope samples no. 3 and 4 are poor, their confidence values are large, that is, the stability grades of slope samples no. 3 and 4 tend to Grade III. The slope samples no. 1 to 2 are basically stable, and the slopes may be loose and deformed in a short time, but there will be no large deformation and damage, and the safety of the slopes is relatively good. The stability of slope samples no. 3 and 4 is poor, various loose fissures may develop on the slope, and
TABLE 8: Comprehensive connection degree of multi-indexes.

\begin{tabular}{lccccc}
\hline Sample slope number & $f_{1}$ & $f_{2}$ & $f_{3}$ & $f_{4}$ & $f_{5}$ \\
\hline 1 & 0.177 & 0.288 & 0.293 & 0.129 & 0.113 \\
2 & 0.100 & 0.115 & 0.436 & 0.181 & 0.168 \\
3 & 0.100 & 0.115 & 0.252 & 0.295 & 0.238 \\
4 & 0.100 & 0.115 & 0.226 & 0.273 & 0.286 \\
\hline
\end{tabular}

serious local deformation and even landslide may occur under certain induced conditions.

The field investigation and monitoring results of the open-pit slope show that the deformation area of the north open-pit slope is mainly concentrated in the front yard of the ancient copper mine site museum - the ground deformation area of the accelerator plant, the ground deformation area of the site museum exhibition hall, and the unstable slope area on the east side of the north open pit [32] (as shown in Figure 4). The field investigation results show that the north open-pit slope is relatively stable in the north and poor in the south, that is, the position of slope samples no. 1 and 2 is relatively stable; the position of slope samples no. 3 and 4 is greatly affected by factors such as slope height, rainfall, and human engineering activities (Tables 4 and 5), and their stability is also relatively poor. However, except for local damage or tension cracks at local step lattice beams and slope tops affected by rainfall or engineering activities (Figure 2), there is no sign of large apparent deformation on the east slope of north open-pit mine after treatment. At present, the east-side slope of north open-pit mine is generally in a stable state, and there is no sign of slip.

5.2. Discussion. To verify the validity and applicability of the proposed EFAHP-SPA model, the fuzzy comprehensive evaluation method $[18,19]$ and the entropy-SPA model [4] were used to evaluate the stability of four sample slopes in the study area, respectively, and the calculation results of the three methods were compared and analyzed. To facilitate the comparative analysis, the weight of fuzzy comprehensive evaluation method is calculated using the subjective weight determined in this paper. In addition, when judging the 
TABLE 9: Evaluation results of slope stability by confidence criterion.

\begin{tabular}{|c|c|c|c|c|c|c|}
\hline \multirow{2}{*}{ Sample slope number } & \multicolumn{5}{|c|}{ Confidence judgment } & \multirow{2}{*}{ Stability grade } \\
\hline & $f_{1}$ & $f_{1}+f_{2}$ & $f_{1}+f_{2}+f_{3}$ & $f_{1}+f_{2}+f_{3}+f_{4}$ & $f_{1}+f_{2}+f_{3}+f_{4}+f_{5}$ & \\
\hline 1 & 0.177 & 0.465 & 0.758 & 0.887 & 1.000 & III \\
\hline 2 & 0.100 & 0.215 & 0.651 & 0.832 & 1.000 & III \\
\hline 3 & 0.100 & 0.215 & 0.467 & 0.762 & 1.000 & IV \\
\hline 4 & 0.100 & 0.215 & 0.441 & 0.714 & 1.000 & IV \\
\hline
\end{tabular}

TABLE 10: Evaluation results of fuzzy comprehensive evaluation method and entropy-SPA method.

\begin{tabular}{lcccccc}
\hline Evaluation method & Slope sample number & $f_{1}$ & $f_{2}$ & $f_{3}$ & $f_{4}$ & $f_{5}$ \\
\hline & 1 & 0.1908 & 0.2168 & 0.2526 & 0.1589 & 0.1809 \\
Fuzzy comprehensive evaluation & 2 & 0.1406 & 0.107 & 0.3256 & 0.2069 & 0.22 \\
& 3 & 0.1406 & 0.107 & 0.1837 & 0.2957 & 0.273 \\
& 4 & 0.1406 & 0.107 & 0.1597 & 0.2763 & 0.3165 \\
\hline & 1 & 0.158 & 0.282 & 0.303 & 0.137 & 0.120 \\
Entropy-SPA & 2 & 0.085 & 0.103 & 0.439 & 0.195 & 0.179 \\
& 3 & 0.085 & 0.103 & 0.246 & 0.314 & 0.253 \\
& 4 & 0.085 & 0.103 & 0.216 & 0.289 & 0.308 \\
\hline
\end{tabular}

TABLE 11: Comparison table of slope stability evaluation results in open-pit mine.

\begin{tabular}{llllc}
\hline Evaluation method/slope sample number & 1 & 2 & 3 & 4 \\
\hline EFAHP-SPA & Basically stable (III) & Basically stable (III) & Unstable (IV) & Unstable (IV) \\
Fuzzy comprehensive evaluation & Basically stable (III) & Basically stable (III) & Unstable (IV) & Extremely unstable (V) \\
Entropy-SPA & Basically stable (III) & Basically stable (III) & Unstable (IV) & Unstable (IV) \\
\hline
\end{tabular}

slope stability grade, the fuzzy comprehensive evaluation method uses the conventional maximum membership principle to judge the stability grade [18], while the entropySPA model uses the confidence criterion to judge the stability grade. The results of slope stability evaluation by these two methods are shown in Tables 10 and 11. It can be seen from Table 11 that the EFAHP-SPA model proposed in this paper is consistent with the evaluation results obtained by entropy-SPA model; however, the results obtained by the fuzzy comprehensive evaluation method are mostly the same, and only the slope evaluation results of sample no. 4 are different. The stability grade of slope sample no. 4 obtained by the fuzzy comprehensive evaluation method is extremely unstable (V), which is obviously inconsistent with the field investigation and monitoring results. If the results of the fuzzy comprehensive evaluation method are judged by the confidence criterion, the stability of slope sample no. 4 is unstable (IV). This also indirectly proves the possible judgment distortion when using the maximum membership principle for fuzzy pattern recognition [28]. To sum up, the comparative analysis of the results of the three research methods shows that the proposed EFAHP-SPA model is feasible to comprehensively evaluate the slope stability of open-pit mine.

\section{Conclusion}

With the increasing scale and depth of open-pit mining, the collapse and landslide geological disaster caused by mining occur frequently, which seriously affects the production safety of the mine as well as surrounding buildings. Taking the east-side slope of Tonglvshan north open-pit mine in Daye as an example, improved set pair analysis method is used to study the slope stability of open-pit mine under the comprehensive influence of multiple factors. The following conclusions are drawn:

(1) To make a systematic and comprehensive evaluation of the slope stability of open-pit mine, based on theoretical analysis, engineering analogy, literature statistics, and expert consultation, an open-pit slope stability evaluation index system with 14 evaluation indexes in four categories: landform, engineering geological characteristics, meteorology, hydrology, and other factors is constructed.

(2) The stability evaluation of open-pit slope is a multifactor evaluation problem. Whether the weighting of evaluation indexes is reasonable will seriously affect the evaluation results of stability. The comprehensive weight optimization model based on information entropy and fuzzy analytic hierarchy process can not only fully consider the influence of human subjective factors, but also reflect the contribution of index measurement, minimize uncertainty, and enhance the rationality of evaluation results.

(3) Aiming at the problems of uncertainty, multifactor, and nonlinearity in the evaluation process of openpit slope stability, an improved set pair analysis model based on information entropy and fuzzy 
analytic hierarchy process is established, the comprehensive weight of evaluation indexes is determined using information entropy theory and FAHP, and the risk grade of open-pit slope is evaluated using confidence criterion. It provides a new reference for slope stability evaluation of open-pit mine.

(4) The proposed EFAHP-SPA model is used to quantitatively evaluate the stability of the east-side slope of Tonglvshan north open-pit mine in Daye. The evaluation results are consistent with the actual situation of the mine. Compared with other existing evaluation methods, the evaluation results are consistent, indicating that the proposed model is effective and feasible.

\section{Data Availability}

The data used to support the findings of this study are available from the corresponding author upon request.

\section{Conflicts of Interest}

The authors declare that they have no potential conflicts of interest.

\section{Acknowledgments}

This research was supported by the National Natural Science Foundation of China (grant no. 52074295) and the Fundamental Research Funds for the Central Universities (grant no. 2021YJSSB13).

\section{References}

[1] T. H. Yang, F. C. Zhang, Q. L. Yu, C. M. Feng, and L. H. Zhou, "Research situation of open-pit mining high and steep slope stability and its developing trend," Rock and Soil Mechanics, vol. 32, no. 05, pp. 1437-1451, 2011.

[2] M. Abdulai and M. Sharifzadeh, "Uncertainty and reliability analysis of open pit rock slopes: a critical review of methods of analysis," Geotechnical \& Geological Engineering, vol. 37, no. 3, pp. 1223-1247, 2019.

[3] T. B. d. Santos, M. S. Lana, T. M. Pereira, and I. Canbulat, "Quantitative hazard assessment system (Has-Q) for open pit mine slopes," International Journal of Mining Science and Technology, vol. 29, no. 3, pp. 419-427, 2019.

[4] X. Zhang, S. W. Zhou, P. Lin, and Z. Tan, "Slope stability evaluation based on entropy coefficient-set pair analysis," Chinese Journal of Rock Mechanics and Engineering, vol. 37, no. S1, pp. 3400-3410, 2018.

[5] H. Yao, Z. Zheng, W. B. Jian, and H. Shen, "Comprehensive evaluation and research on stability of high lithological slope of expressway," Chinese Journal of Geotechnical Engineering, vol. 28 , no. 5, pp. 558-563, 2006.

[6] Q. Wang, M. He, S. Li et al., "Comparative study of model tests on automatically formed roadway and gob-side entry driving in deep coal mines," International Journal of Mining Science and Technology, vol. 31, no. 4, pp. 591-601, 2021.

[7] Z. H. Qin and P. Qin, "Evaluation coupling model for high slope stability based on fuzzy analytical hierarchy process- set pair analysis method," Chinese Journal of Geotechnical Engineering, vol. 32, no. 5, pp. 706-711, 2010.
[8] B. Azarfar, S. Ahmadvand, J. Sattarvand, and B. Abbasi, "Stability analysis of rock structure in large slopes and openpit mine: numerical and experimental fault modeling," Rock Mechanics and Rock Engineering, vol. 52, no. 12, pp. 48894905, 2019.

[9] Q. Wang, Y. Wang, M. C. He et al., "Experimental research and application of automatically formed roadway without advance tunneling," Tunnelling and Underground Space Technology, vol. 114, Article ID 103999, 2021.

[10] M. Wang, X. Wang, Q. Liu, F. Shen, and J. Jin, "A novel multidimensional cloud model coupled with connection numbers theory for evaluation of slope stability," Applied Mathematical Modelling, vol. 77, pp. 426-438, 2020.

[11] F. Wu, H. Zhang, Q. Zou, C. Li, J. Chen, and R. Gao, "Viscoelastic-plastic damage creep model for salt rock based on fractional derivative theory," Mechanics of Materials, vol. 150, Article ID 103600, 2020.

[12] C. Qi and X. Tang, "A hybrid ensemble method for improved prediction of slope stability," International Journal for $\mathrm{Nu}$ merical and Analytical Methods in Geomechanics, vol. 42, no. 15, pp. 1823-1839, 2018.

[13] Q. Yin, J. Y. Wu, C. Zhu, M. He, Q. Meng, and H. Jing, "Shear mechanical responses of sandstone exposed to high temperature under constant normal stiffness boundary conditions," Geomechanics and Geophysics for Geo-Energy and GeoResources, vol. 7, no. 2, pp. 1-17, 2021.

[14] X. P. Zhou and H. Cheng, "Analysis of stability of threedimensional slopes using the rigorous limit equilibrium method," Engineering Geology, vol. 160, pp. 21-33, 2013.

[15] Z. Chun, H. M. Chao, Z. X. Hu, T. Z. Gang, Y. Qian, and L. L. Feng, "Nonlinear mechanical model of constant resistance and large deformation bolt and influence parameters analysis of constant resistance behavior," Rock and Soil Mechanics, vol. 42, no. 7, pp. 1911-1924, 2021.

[16] G. S. Liu, C. M. Qi, C. L. Ni, and J. Hu, "Set pair analysis of slope stability evaluation based on combination weighting game theory," Journal of Yangtze River Scientific Research Institute, vol. 31, no. 6, pp. 83-88, 2014.

[17] F. Kang, B. Xu, J. Li, and S. Zhao, "Slope stability evaluation using Gaussian processes with various covariance functions," Applied Soft Computing, vol. 60, pp. 387-396, 2017.

[18] X. Yang, D. Hou, Z. Hao, and X. J. Yang, "Fuzzy comprehensive evaluation of landslide caused by underground mining subsidence and its monitoring," International Journal of Environment and Pollution, vol. 59, no. 2-4, pp. 284-302, 2016.

[19] Q. Yao, X. Yang, and H. Li, "A fuzzy AHP-based method for comprehensive blasting vibration comfort evaluation forecast," Advances in Civil Engineering, vol. 2020, pp. 1-11, Article ID 8919314, 2020.

[20] Y. Achour, A. Boumezbeur, R. Hadji, A. Chouabbi, V. Cavaleiro, and E. A. Bendaoud, "Landslide susceptibility mapping using analytic hierarchy process and information value methods along a highway road section in Constantine, Algeria," Arabian Journal of Geosciences, vol. 10, no. 8, p. 194, 2017.

[21] B. Zhao, Y. Zhao, and J. Wang, "New stability forecasting model for goaf slope based on the AHP-TOPSIS theory," Arabian Journal of Geosciences, vol. 14, no. 1, pp. 1-12, 2021.

[22] Z. Q. Sun and J. T. Li, "Study on open-pit mine slope stability based on improved TOPSIS method," in Proceedings of the IOP Conference Series: Earth and Environmental Science, June 2021, Article ID 022045. 
[23] S. K. Das, R. K. Biswal, N. Sivakugan, and B. Das, "Classification of slopes and prediction of factor of safety using differential evolution neural networks," Environmental Earth Sciences, vol. 64, no. 1, pp. 201-210, 2011.

[24] Y. Erzin and T. Cetin, "The prediction of the critical factor of safety of homogeneous finite slopes using neural networks and multiple regressions," Computers \& Geosciences, vol. 51, pp. 305-313, 2013.

[25] Z. G. Tao, D. D. Zhao, X. J. Yang, W. JiaMin, and S. Yu, "Evaluation of open-pit mine security risk based on FAHPextenics matter-element model," Geotechnical \& Geological Engineering, vol. 38, no. 2, pp. 1653-1667, 2020.

[26] C. Qiao, Y. Wang, C. H. Li, and B. Q. Yan, "Application of extension theory based on improved entropy weight method to rock slope analysis in cold regions," Geotechnical \& Geological Engineering, vol. 1-13, 2021.

[27] K. Q. Zhao, Set Pair Analysis and its Application, Zhejiang Science and Technology Press, Hangzhou, China, 2000.

[28] X. S. Lin, "Safety evaluation of highway slope with the set pair analysis model," Journal of South China Normal University (Social Science Edition), vol. 36, no. 06, pp. 28-33, 2011.

[29] Y. Y. Liu, Z. Z. Guo, Y. Q. Li, and Y. P. Li, "Risk assessment model of highway slope based on entropy weight set pair analysis and vehicle laser scanning," Rock and Soil Mechanics, vol. 39, no. S2, pp. 131-141, 2018.

[30] W. S. Wang and Y. Q. Li, "Hazard degree assessment of landslide using set pair analysis method," Natural Hazards, vol. 60, no. 2, pp. 367-379, 2012.

[31] F.-G. Yang, Y. Liang, V. P. Singh et al., "Debris flow hazard assessment using set pair analysis models: take Beichuan county as an example," Journal of Mountain Science, vol. 11, no. 4, pp. 1015-1022, 2014

[32] Z. G. Tao, C. Zhu, X. H. Zheng, and M. He, "Slope stability evaluation and monitoring of Tonglushan ancient copper mine relics," Advances in Mechanical Engineering, vol. 10, no. 8, Article ID 1687814018791707, 2018.

[33] C. Tan, Y. Song, and H. Che, "Application of set pair analysis method on occupational hazard of coal mining," Safety Science, vol. 92, pp. 10-16, 2017.

[34] T. L. Saaty, "Decision making - the analytic hierarchy and network processes (AHP/ANP)," Journal of Systems Science and Systems Engineering, vol. 13, no. 1, pp. 1-35, 2004.

[35] Q. F. Hu, L. Fan, and Z. J. Dong, "Application of modified analytic hierarchy process based on fuzzy comprehensive evaluation to landslide risk assessment," Journal of Yangtze River Scientific Research Institute, vol. 31, no. 5, pp. 29-33, 2014.

[36] J. Zhang, P. He, J. Xiao, and F. Xu, "Risk assessment model of expansive soil slope stability based on Fuzzy-AHP method and its engineering application," Geomatics, Natural Hazards and Risk, vol. 9, no. 1, pp. 389-402, 2018.

[37] Z. S. Xu, "Algorithm for priority of fuzzy complementary judgement matrix," Journal of Systems Engineering, vol. 16, no. 4, pp. 311-314, 2001.

[38] H. Y. Chen and J. B. Zhao, "Research on compatibility of fuzzy judgement matrices," Operations Research and Management Science, vol. 13, no. 1, pp. 44-47, 2004.

[39] C. E. Shannon, "A mathematical theory of communication," ACM SIGMOBILE Mobile Computing and Communications Review, vol. 5, no. 1, pp. 3-55, 2001.

[40] J. Davis and L. Blesius, "A hybrid physical and maximumentropy landslide susceptibility model," Entropy, vol. 17, no. 6, pp. 4271-4292, 2015.
[41] Y. L. Jiang and Z. S. Deng, "Application of extension analytical hierarchy process-set pair model in evaluation of slope stability," Highways, vol. 61, no. 10, pp. 13-18, 2016.

[42] S. Y. Wen, J. L. Li, X. T. Yang, and X. T. Liu, "Multistage fuzzy comprehensive evaluation for analyzing unloading high-steep slope stability," Rock and Soil Mechanics, vol. 27, no. 11, pp. 2041-2044, 2006.

[43] S. J. Wang, C. Lee, and Z. Yue, "Global quality of rock works for permanent shiplock of the three gorges project on Yangtze river, China," Chinese Journal of Rock Mechanics and Engineering, vol. 20, no. 5, pp. 589-596, 2001. 